\section{(6) OPEN ACCESS}

Health Sciences, University of Leicester, Leicester, UK

\section{Correspondence to} Sarah Emma Seaton, Health Sciences, University of Leicester, 22-28 Princess Road West, Leicester LE1 6TP, UK; sarah.seaton@le.ac.uk

Received 19 December 2011 Accepted 17 February 2012 Published Online First 19 April 2012
To cite: Seaton SE, King $S$ Manktelow BN, et al. Arch Dis Child Fetal Neonatal Ed 2013, 98, F15-F20.

\title{
Babies born at the threshold of viability: changes in survival and workload over 20 years
}

\author{
Sarah E Seaton, Sophie King, Bradley N Manktelow, Elizabeth S Draper, David J Field
}

\section{ABSTRACT}

Objective To assess the care given to the babies born at the threshold of viability over the last 20 years using regional and national data.

Design Population-based retrospective study.

Setting Former 'Trent' health region.

Participants Babies born between 1 January 1991

and 31 December 2010 at $22^{+0}$ to $25^{+6}$ weeks

gestational age.

Main outcome measure Survival and use of respiratory support.

Methods Data of all babies born between 1 January 1991 and 31 December 2010 with a gestational age of $22^{+0}$ to $25^{+6}$ weeks and admitted to a neonatal unit were extracted from The Neonatal Survey. Use of respiratory support in terms of ventilation and continuous positive airway pressure (CPAP) for this group of babies was calculated as a proportion of the total used by the whole neonatal intensive care population within the defined study area.

Results The proportion of babies surviving to discharge increased significantly over time in those born at 24 and 25 weeks $(p<0.01)$ but failed to achieve statistical significance for those at 23 weeks $(p=0.08)$. No babies born at 22 weeks survived. The babies born at 22-25 weeks accounted for $26.3 \%$ of all ventilation and $21.5 \%$ of CPAP given.

Conclusion Our work concurs with the current UK guidelines. There could be advantages in focusing the care of babies born at 23 weeks to a small number of intensive care units to allow specialist expertise to develop in all aspects of the management of these babies. However, focusing care will not necessarily improve survival or reduce morbidity.

\section{BACKGROUND}

Although relatively small in number, babies born at or around the limit of viability generate a great deal of public interest and a range of often polarised opinions.

In recent years, the Nuffield Council for Bioethics has reviewed the evidence surrounding the appropriateness of treatment for such babies and updated UK professional guidance has been published. ${ }^{12}$ In broad terms, these documents suggest that before 23 weeks of gestation, intervention is not appropriate; at 23 weeks, health professionals should discuss with parents the provision of active intervention given the individual circumstances; while at 24 weeks, the broad expectation would be to proceed with active intervention and intensive care unless a baby was in very poor condition at birth.

Recently one mother has campaigned for a review of these guidelines, particularly with regard to how they relate to the care given to babies born

\section{What is known on this topic}

Babies born at the threshold of viability create a wide range of polarised opinions regarding decisions about their care and management.

- Current recommendations suggest babies born at 24 weeks of gestation should normally receive active intervention while babies born at 23 weeks of gestation should be discussed with parents regarding whether such intervention is appropriate.

\section{What this paper adds}

- This work demonstrates that babies of 25 weeks of gestation or less consume a very significant amount of intensive care.

- The resources allocated to these babies have increased over time, and survival has significantly increased in babies born at 24 and 25 weeks.

- There has been little change in the outcome of babies born at 23 weeks of gestation in the UK over 20 years and many ultimately die.

at 21 and 22 weeks following the birth and death of her son at $21^{+5}$ weeks of gestation. ${ }^{3}$ In direct contrast, a recent documentary (The Price of Life, by Adam Wishart $)^{4}$ debated the issues surrounding active intervention for babies born at 23 weeks gestation given their high mortality and equally high morbidity rate among survivors. In other countries, such as The Netherlands, current policy follows a non-interventionist stance for babies at the limits of viability. $^{5}$

Such differing views were a prominent part of the 2008 abortion debate. ${ }^{6}$ One additional factor that emerged at that time was the extent to which outcome, particularly survival, could be related to how hard a particular neonatal service tried to keep such babies alive; even though such data cannot be considered generalisable. ${ }^{7}$

This area remains controversial with only limited data about the care provided to babies born at the extreme of prematurity in the UK over time. ${ }^{8}$ While the two EPICure studies $9{ }^{10}$ have provided excellent snapshots in the UK, and studies elsewhere have provided similar data regarding other parts of the world, ${ }^{11-14}$ it is difficult to unravel trends in management or outcome. 
We have used existing national and regional datasets to explore the patterns of care provided to these babies over 20 years. This work focuses particularly on changes in the immediate decision making following birth, resource use and short-term outcome during this period.

\section{METHODS}

Data of all babies born between 1 January 1991 and 31 December 2010 with a gestational age of $22^{+0}$ to $25^{+6}$ weeks and admitted to a neonatal unit were extracted from The Neonatal Survey (TNS). TNS is an ongoing study of neonatal care activity in the East Midlands and Yorkshire regions of the UK. The inclusion criteria for the study include all babies born less than or equal to 32 weeks of gestation. The area covered by TNS has changed over time and to allow for a constant population, this work included only babies born to a mother resident in the former 'Trent' health region (as defined in 1990) - the original TNS population. ${ }^{15}$

Data were also obtained from the Centre for Maternal and Child Enquiries (CMACE). When first established in the early 1990s (then known as the Confidential Enquiry into Stillbirths and Deaths in Infancy), this organisation collated data from various sources concerning deaths of all infants delivered after 22 weeks gestation either born dead or who died in the first year of life. Using the data from this source it was possible to extract information for the population covered by TNS concerning the number of babies who were alive at the onset of labour, the number of babies who died during labour and the number who died before admission to a neonatal unit. Due to changes in the national inclusion criteria used by CMACE over time, this particular dataset was only available for the period 1996-2005.

Data on the number of live births in the region were obtained from the Office of National Statistics.

In order to examine time trends, the 20-year time period covered by the study was divided into four 5 -year bands: 19911995, 1996-2000, 2001-2005 and 2006-2010. This grouping of years compensated for the small number of babies born at the extremes of prematurity. A small number of babies were discharged to hospitals not covered by TNS. Where it was possible, clinical details were used to allocate these babies as either deaths or survivors and when not possible, these babies were removed from the analysis. Babies which were deemed to have implausible birthweights for their gestational age (more than three SD from the median birthweight for their gestation and gender) were removed from the analysis.

Stacked bar charts were created to visually represent the proportion of $22^{+0}-25^{+6}$ week fetuses that died during labour, the proportion of babies which died before admission to the neonatal unit, the proportion that died after admission and the proportion that survived to discharge as a proportion of those alive at the onset of labour. The proportion of babies $22^{+0}$ to $25^{+6}$ surviving to discharge following admission for neonatal care by week of gestational age was also investigated using a $\chi^{2}$ test for trend.

For $22^{+0}$ - to $25^{+6}$-week babies, resource use was investigated based on the proportion of key interventions (days of ventilation - all types; days of continuous positive airway pressure (CPAP) used compared to that expended on the whole neonatal intensive care population. Using a $\chi^{2}$ test for trend, this analysis was then repeated with a focus on the proportion of care that was given to babies that ultimately died.

The median length of stay for the babies that survived and those that died was calculated by week of gestational age over time. P values were calculated using Kendalls Tau to measure the association between length of stay in hospital and time period.

STATA v11.2 was used for all analysis of data. Statistical significance for all tests was set at the 5\% level.

\section{RESULTS}

Between 1 January 1991 and 31 December 2010, 1659 babies were identified as admitted to neonatal intensive care and born at $22^{+0}$ to $25^{+6}$ weeks' gestational age to a mother resident in the former Trent health region. Of these babies, 71 (4.3\%) had no outcome recorded on the database as they were transferred to a hospital out of the TNS region before discharge from hospital. After clinical review of their individual data collection forms by a neonatal consultant, it was possible to allocate 62 babies an outcome (alive or dead) and these babies were then included in all analyses. The remaining nine $(0.5 \%)$ were excluded. A further 16 babies were removed from the analyses because of implausible birthweights for their gestational age (more than three SD from the median for their gestational age and gender). In total, 1634 babies were included in the analysis.

From 1996 to 2005, 558 babies of the specified gestational age were identified by CMACE as having died before admission to the neonatal unit. Of these, $72(12.9 \%)$ died before labour; 193 (34.6\%) died during labour and 293 (52.5\%) died on the labour suite. Figure 1 presents the proportion of each outcome for each week of gestation for 1996-2000 and 2001-2005 and shows that outcomes, in particular in terms of survival, are relatively stable for the 22- and 23-week babies. An increase in survival occurred for 24- and 25 -week babies in the more recent time period.

Table 1 identifies the number of babies at each week of gestation admitted to neonatal care as a rate of the total live births, over the four periods of the study.

Of the 1634 babies admitted to neonatal care, 659 (40.3\%) babies survived to discharge (table 2). There was a significant increase in the proportion of babies surviving over the four time periods from $27.5 \%$ in 1991 to 1995 to $50.2 \%$ in 2006 to $2010(p<0.001)$. None of the 22 -week babies over the 20 -year time period survived. In contrast, $15.0 \%$ of 23 -week babies, $34.6 \%$ of 24 -week babies and $55.4 \%$ of 25 -week babies survived (table 2). There was a trend over the 20 years for increased survival and at 24 and 25 weeks of gestation, this change was highly statistically significant $(p<0.01)$. Although the survival of 23 -week babies has improved, this failed to achieve statistical significance $(\mathrm{p}=0.08)$.

The number of days of ventilation and of CPAP used in caring for these babies is given in table 3 and as a proportion of total ventilation or CPAP use for all admissions to neonatal care at all gestational ages. Data for babies of 22 weeks of gestation are based on too few patients for any trend to be clear but for babies of 23, 24 and 25 weeks gestational age, the trend is one of increasing resource use (all p values <0.001). This is especially true when one considers the combined totals for ventilation and CPAP to take into account the changing approach to respiratory support (greater use of CPAP) over this time. Over the whole 20 years, the babies born at 22-25 weeks gestational age accounted for $26.3 \%$ of the total days of ventilation and $21.5 \%$ of total CPAP days given to all babies admitted to neonatal care (table 3 ).

Of days of ventilation and CPAP given to babies born at 2225 weeks gestational age, $34.8 \%$ of the ventilation days and 9.6\% of the CPAP days were given to babies who ultimately died (table 4). For 2006-2010, the proportions of care given to 
Figure 1 Proportion of each outcome by gestational age ( 22 to 25 weeks) for all babies alive at the onset of labour: former 'Trent' health region 1996 to 2000 and 2001 to 2005.

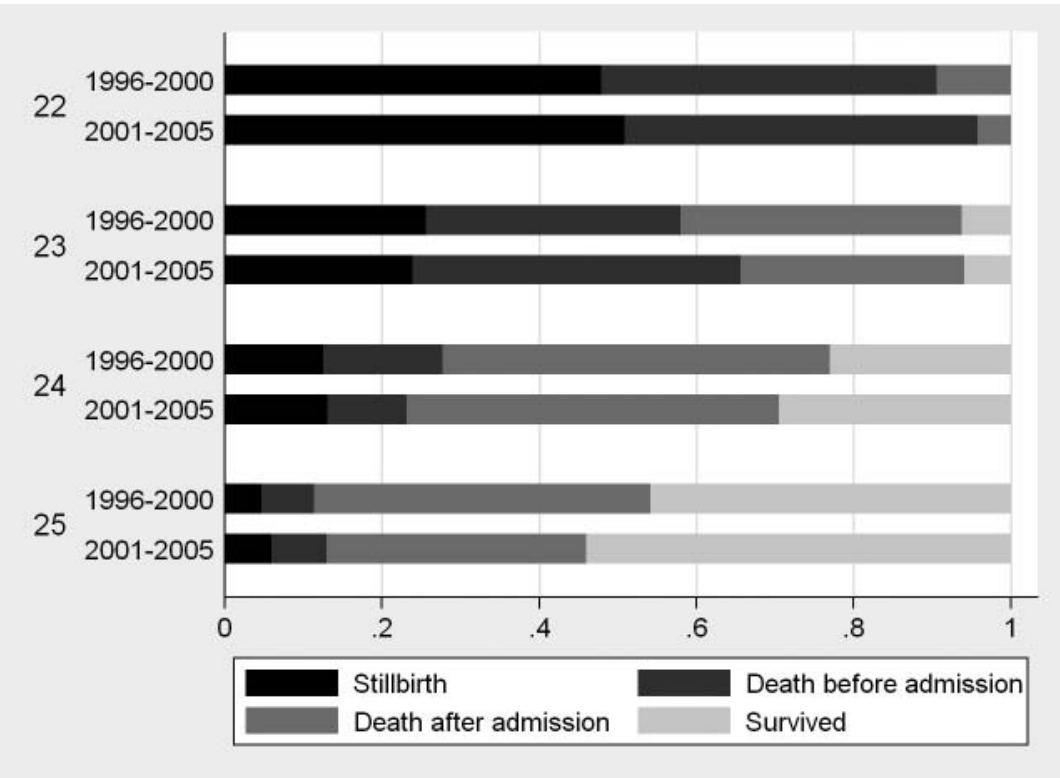

babies who ultimately died were higher than in the preceding years (8.2\% of ventilation and $10.0 \%$ of CPAP).

Table 5 shows the length of stay for each gestation group over time for those babies who died before discharge. This table has been created excluding the 62 babies that died outside the geographical boundaries used by TNS as it was not possible to determine how long they remained in neonatal care. Excluding the data for babies at 22 weeks of gestation, as the number of these babies is very small, the pattern has been towards deaths at a later age (all $\mathrm{p}$ values $<0.001$ ). Table 6 shows equivalent data for surviving babies where no clear trend emerged (all $\mathrm{p}$ values $>0.05$ ).

\section{DISCUSSION}

The data from this study highlight the issues that surround this group of babies. For births at 24 and 25 weeks of gestation, there appears to have been an increasing readiness to provide intensive care over the 20 years of our study. This has been matched by improved survival but at the cost of very significant resource use as measured in terms of days of respiratory support. We have measured neurodevelopmental outcome in this cohort on two occasions and the data indicate that rates of adverse outcome in the whole cohort are relatively high at around $30 \%$ of survivors. ${ }^{16}$

At 22 weeks, the converse is true. In our study, there were no survivors over a 20 -year period and hence the current policy in $\mathrm{UK}^{2}$ (and indeed in many other countries) ${ }^{5} 17$ of providing comfort care for these babies seems to be correct. Whether a more aggressive policy towards these babies would provide a different and perhaps more encouraging outcome seems unlikely without first seeing an improving picture for babies born at 23 weeks of gestation. However, in some parts of the world there appears to be both a greater willingness to provide full intensive care to babies at 22 weeks of gestation and somewhat better results. ${ }^{18}$

It is at 23 weeks of gestation that there appears to be a watershed. The pattern of survival over 20 years is one of increase although the scale of change is quite different to that seen for babies at 24 and 25 weeks of gestation. While the test for trend does not quite reach significance the study was not planned to be powered to measure a particular change in mortality and a bigger study may well have crossed the threshold for statistical significance. However, the issue of clinical significance is somewhat different as it is highly probable that any change in survival may have been at the cost of high rates of disability. There is no suggestion that the different pattern of outcome for babies at 23 weeks of gestation has been because of a lack of enthusiasm to support such babies as the amount of respiratory support has risen markedly in the last 15 years of the study with a large proportion of the ventilator support that went to babies at this gestation given to those who ultimately died. In general, over time, these deaths occurred later than in earlier years. Our data suggest therefore that despite all that intensive care has to offer currently, there has been no clear benefit at 23 weeks of gestation.

So what implications do these data have for the various issues surrounding this group of babies and are the current

Table 1 Number of babies admitted to the neonatal intensive care unit by gestation in weeks and birth year category (Rate per 10000 live births in the region in the corresponding year group)

\begin{tabular}{|c|c|c|c|c|c|}
\hline \multirow[b]{2}{*}{ Birth year } & \multicolumn{5}{|c|}{ Gestation (weeks) } \\
\hline & $\begin{array}{l}22 \mathrm{n} \\
\text { (rate per } 10000 \text { births) }\end{array}$ & $\begin{array}{l}23 \mathrm{n} \\
\text { (rate per } 10000 \text { births) }\end{array}$ & $\begin{array}{l}24 \mathrm{n} \\
\text { (rate per } 10000 \text { births) }\end{array}$ & $\begin{array}{l}25 \mathrm{n} \\
\text { (rate per } 10000 \text { births) }\end{array}$ & $\begin{array}{l}\text { Total } n \\
\text { (rate per } 10000 \text { births) }\end{array}$ \\
\hline 1991-1995 & $14(0.5)$ & $56(1.8)$ & $141(4.6)$ & $179(5.9)$ & 390 (12.9) \\
\hline 1996-2000 & $11(0.4)$ & $77(2.8)$ & $139(5.1)$ & $183(6.7)$ & $410(14.9)$ \\
\hline 2001-2005 & $5(0.2)$ & $47(1.8)$ & $164(6.2)$ & $182(6.9)$ & $398(15.0)$ \\
\hline 2006-2010 & $1(0.03)$ & $80(2.7)$ & $151(5.0)$ & $204(6.8)$ & $436(14.5)$ \\
\hline Total & $31(0.3)$ & $260(2.3)$ & $595(5.2)$ & $748(6.5)$ & $1,634(14.3)$ \\
\hline
\end{tabular}


Table 2 Number of babies surviving to discharge at each gestational age in each birth year category (\% surviving of those admitted)

\begin{tabular}{|c|c|c|c|c|c|}
\hline \multirow[b]{2}{*}{ Birth year } & \multicolumn{5}{|c|}{ Gestational age (completed weeks) } \\
\hline & $22 \mathrm{n}(\%)$ & $23 \mathrm{n}(\%)$ & 24 n (\%) & $25 \mathrm{n}(\%)$ & Total n (\%) \\
\hline 1991-1995 & $0(0 \%)$ & $4(7.1 \%)$ & $31(22.0 \%)$ & $72(40.2 \%)$ & $107(27.5 \%)$ \\
\hline 1996-2000 & $0(0 \%)$ & $11(14.3 \%)$ & $44(31.7 \%)$ & $93(50.8 \%)$ & $148(36.1 \%)$ \\
\hline $2001-2005$ & $0(0 \%)$ & $8(17.0 \%)$ & $65(39.7 \%)$ & $112(61.5 \%)$ & $185(46.5 \%)$ \\
\hline $2006-2010$ & $0(0 \%)$ & $16(20.0 \%)$ & $66(43.7 \%)$ & $137(67.2 \%)$ & $219(50.2 \%)$ \\
\hline Total & $0(0 \%)$ & $39(15.0 \%)$ & $206(34.6 \%)$ & $414(55.4 \%)$ & $659(40.3 \%)$ \\
\hline $\mathrm{p}$ Value: test for trend & - & 0.08 & 0.004 & 0.002 & $<0.001$ \\
\hline
\end{tabular}

management guidelines appropriate both in the UK and in other countries with similar approaches to these babies? In relation to babies born at 24 and 25 weeks of gestation, survival to discharge for babies was approximately $44 \%$ and $67 \%$, respectively in the most recent 5 years, and given that late deaths are not common, it would seem unacceptable to consider anything other than an expectation of active treatment for such babies. Perhaps more important is that the trend in the data over time is for improvement. This suggests that current technologies are improving the outlook for these babies and hence it would seem perverse not to consider an active approach in such babies as the norm.

For babies born at 22 weeks of gestation, the opposite appears to be true as no survivors were recorded. The only trend in the data appears to be a steady reduction in the number of babies even considered for intensive care. The number of CPAP and ventilation days received by the 22 weeks gestational age babies reflected the care pathway of a very small number of babies who all ultimately died. A palliative approach to the baby and his or her family therefore seems appropriate in terms of what current technology appears to be able to offer but this position should be subject to review if the outcome for 23-week gestation babies was to change significantly in the future.

The situation regarding babies of 23 weeks gestation presents the most complex challenge. In relation to the link with the abortion limit, the study includes data to support the view that 23 weeks represents the limit of our current technology and that this situation has not shown significant change over 20 years.

The current clinical guidelines regarding the management of babies born at 23 weeks of gestation suggest that the decision to offer active treatment should be made jointly between the clinical team and the parents with the expectation that for many babies active intervention would not be appropriate. Clearly a range of factors impact on what actually happens such as the time available for counselling and discussion, the experience of the clinicians present, the understanding and background of the parents and the condition of the baby when born. Given that some key elements of the process cannot easily be controlled, in many cases attempting resuscitation is the 'default' position. It is this issue which has been the subject of media debate and whether, as in The Netherlands, at 23 weeks of gestation, resuscitation should not be attempted. ${ }^{5}$

However, this view assumes that 23-week gestation babies are a unique group within neonatal care whose difficulties and poor outlook are not shared by other groups and this is clearly not true. Similar issues can be raised in relation to babies born with a range of congenital abnormalities. Fortunately, the numbers of each individual anomaly carrying a similarly poor prognosis are small and hence they have less impact but considered as a group, their outlook is also equivalent to that of the most immature babies. This inevitably leads to the question of whether it is reasonable to abandon active care for all babies who share a poor overall prognosis? Such a position would seem untenable

Table 3 The total number of days of ventilation and CPAP by gestational age and year group, and as a percentage of the total number of days ventilation or CPAP for babies of all gestational ages admitted to neonatal care

\begin{tabular}{|c|c|c|c|c|c|}
\hline \multirow[b]{2}{*}{ Birth year } & \multicolumn{5}{|c|}{ Gestational age (completed weeks) } \\
\hline & 22 n (\%) & 23 n (\%) & 24 n (\%) & $25 \mathrm{n}(\%)$ & Total n (\%) \\
\hline \multicolumn{6}{|l|}{ Ventilation } \\
\hline 1991-1995 & $32(0.1 \%)$ & $550(1.9 \%)$ & $1964(6.9 \%)$ & $2682(9.5 \%)$ & $5228(18.4 \%)$ \\
\hline 1996-2000 & $37(0.1 \%)$ & $743(3.0 \%)$ & $1858(7.5 \%)$ & $2697(10.9 \%)$ & $5335(21.5 \%)$ \\
\hline $2001-2005$ & $3(<0.1 \%)$ & $810(3.4 \%)$ & $3194(13.4 \%)$ & $3691(15.5 \%)$ & $7698(32.3 \%)$ \\
\hline 2006-2010 & $76(0.3 \%)$ & $1844(6.7 \%)$ & $3037(11.1 \%)$ & $4209(15.4 \%)$ & $9166(33.5 \%)$ \\
\hline Total & $148(0.1 \%)$ & $3947(3.8 \%)$ & $10053(9.6 \%)$ & $13279(12.7 \%)$ & $27427(26.3 \%)$ \\
\hline$p$ Value: test for trend & $<0.001$ & $<0.001$ & $<0.001$ & $<0.001$ & $<0.001$ \\
\hline \multicolumn{6}{|l|}{ CPAP } \\
\hline 1991-1995 & $0(0 \%)$ & $8(0.1 \%)$ & $363(6.3 \%)$ & $354(6.2 \%)$ & $725(12.7 \%)$ \\
\hline 1996-2000 & $0(0 \%)$ & $170(1.1 \%)$ & $1260(8.3 \%)$ & $1682(11.1 \%)$ & $3112(20.6 \%)$ \\
\hline $2001-2005$ & $0(0 \%)$ & $499(1.5 \%)$ & $2363(7.2 \%)$ & $4307(13.2 \%)$ & $7169(22.0 \%)$ \\
\hline 2006-2010 & $3(<0.1 \%)$ & $847(2.1 \%)$ & $2580(6.5 \%)$ & $5620(14.1 \%)$ & $9050(22.8 \%)$ \\
\hline Total & $3(<0.1 \%)$ & $1524(1.6 \%)$ & $6566(7.0 \%)$ & $11963(12.8 \%)$ & $20056(21.5 \%)$ \\
\hline$p$ Value: test for trend & 0.099 & $<0.001$ & $<0.001$ & $<0.001$ & $<0.001$ \\
\hline
\end{tabular}


Table 4 The total number of days of ventilation or CPAP for babies who died before discharge by gestational age and year group, with percentage of the total number of days ventilation or CPAP for all babies of that gestational age admitted to neonatal care

\begin{tabular}{|c|c|c|c|c|c|}
\hline \multirow[b]{2}{*}{ Birth Year } & \multicolumn{5}{|c|}{ Gestational age (completed weeks) } \\
\hline & 22 n (\%) & 23 n (\%) & 24 n (\%) & 25 n (\%) & Total n (\%) \\
\hline \multicolumn{6}{|l|}{ Ventilation } \\
\hline 1991-1995 & $\begin{array}{c}32 \\
100 \%\end{array}$ & $\begin{array}{c}417 \\
83.4 \%\end{array}$ & $\begin{array}{c}695 \\
35.4 \%\end{array}$ & $\begin{array}{c}814 \\
30.4 \%\end{array}$ & $\begin{array}{c}1958 \\
37.5 \%\end{array}$ \\
\hline $1996-2000$ & $\begin{array}{c}37 \\
100 \%\end{array}$ & $\begin{array}{c}306 \\
41.2 \%\end{array}$ & $\begin{array}{c}572 \\
30.8 \%\end{array}$ & $\begin{array}{c}615 \\
22.8 \%\end{array}$ & $\begin{array}{c}1530 \\
28.7 \%\end{array}$ \\
\hline $2001-2005$ & $\begin{array}{c}3 \\
100 \%\end{array}$ & $\begin{array}{c}445 \\
54.9 \%\end{array}$ & $\begin{array}{c}1055 \\
33.0 \%\end{array}$ & $\begin{array}{c}1061 \\
28.7 \%\end{array}$ & $\begin{array}{c}2564 \\
33.3 \%\end{array}$ \\
\hline $2006-2010$ & $\begin{array}{c}76 \\
100 \%\end{array}$ & $\begin{array}{c}1135 \\
61.6 \%\end{array}$ & $\begin{array}{c}1251 \\
40.2 \%\end{array}$ & $\begin{array}{c}1042 \\
24.8 \%\end{array}$ & $\begin{array}{c}3504 \\
38.2 \%\end{array}$ \\
\hline Total & $\begin{array}{c}148 \\
100 \%\end{array}$ & $\begin{array}{c}2303 \\
58.3 \%\end{array}$ & $\begin{array}{c}3573 \\
35.5 \%\end{array}$ & $\begin{array}{c}3532 \\
26.6 \%\end{array}$ & $\begin{array}{c}9556 \\
34.8 \%\end{array}$ \\
\hline$p$ Value: test for trend CPAP & - & 0.56 & $<0.001$ & 0.02 & 0.004 \\
\hline 1991-1995 & $\begin{array}{c}0 \\
0 \%\end{array}$ & $\begin{array}{c}2 \\
25 \%\end{array}$ & $\begin{array}{c}125 \\
34.4 \%\end{array}$ & $\begin{array}{c}63 \\
17.8 \%\end{array}$ & $\begin{array}{c}190 \\
26.2 \%\end{array}$ \\
\hline $1996-2000$ & $\begin{array}{c}0 \\
0 \%\end{array}$ & $\begin{array}{c}1 \\
0.6 \%\end{array}$ & $\begin{array}{c}128 \\
10.2 \%\end{array}$ & $\begin{array}{c}67 \\
4.0 \%\end{array}$ & $\begin{array}{c}196 \\
6.3 \%\end{array}$ \\
\hline 2001-2005 & $\begin{array}{c}0 \\
0 \%\end{array}$ & $\begin{array}{c}41 \\
9.1 \%\end{array}$ & $\begin{array}{c}144 \\
6.1 \%\end{array}$ & $\begin{array}{c}447 \\
10.4 \%\end{array}$ & $\begin{array}{c}632 \\
8.8 \%\end{array}$ \\
\hline $2006-2010$ & $\begin{array}{c}3 \\
100 \%\end{array}$ & $\begin{array}{c}231 \\
27.3 \%\end{array}$ & $\begin{array}{c}322 \\
12.5 \%\end{array}$ & $\begin{array}{c}349 \\
6.2 \%\end{array}$ & $\begin{array}{c}905 \\
10.0 \%\end{array}$ \\
\hline Total & $\begin{array}{c}3 \\
100 \%\end{array}$ & $\begin{array}{c}275 \\
17.7 \%\end{array}$ & $\begin{array}{c}719 \\
11.0 \%\end{array}$ & $\begin{array}{c}926 \\
7.7 \%\end{array}$ & $\begin{array}{l}1923 \\
9.6 \%\end{array}$ \\
\hline$p$ Value: test for trend & - & $<0.001$ & $<0.001$ & $<0.001$ & 0.009 \\
\hline
\end{tabular}

since if active care is never attempted, then future progress would be extremely unlikely.

The data from this study in relation to babies born at 23 weeks of gestation also raise the issue of whether the current model for delivery of care to these babies is correct. At present, they are dispersed between 50 or more intensive care units in the UK and it seems important to consider whether instead there would be advantages to focusing the care of 23 -week gestation babies to a smaller group of intensive care units. For the UK, and many developed countries, this would mean that such a unit would serve an extended catchment area (unlike the situation for other babies needing intensive care where the norm would be that care would continue to be within the local network/geographical area). While the circumstances of delivery will not always permit this, for a proportion, it would be possible to arrange either delivery at such a unit or at the very least early transfer. At present in the UK, even the biggest intensive care units have only a handful of such babies a year. Centralising their care would allow specialist expertise to develop in all aspects of the management of these babies including judgements about subtle influences on outcome such as whether the baby is just 23 weeks or 23 weeks and 6 days. Certainly there are reports from around the world that suggest highly specialist care can offer better outcomes at the extremes of viability. ${ }^{19} 20$

A greater centralisation of care might also help to deal with the high proportion of resource expended on babies who later died. In babies born at 23 weeks of gestation, currently around $58 \%$ of the days of ventilation are given to babies that die before discharge. Focusing the care of these babies to a limited number of intensive care units should permit neonatologists to identify, with increased confidence, when a baby's course was either no longer compatible with long-term survival and/or a reasonable quality of life. This would then facilitate discussions regarding re-orientation of care from an intensive to a palliative approach occurring, when necessary, in a timely fashion. Parents could be confident that the team looking after their baby and providing counselling had particular expertise in caring for babies born extremely premature.

We have no data from our study to specifically support such a change in the delivery of care. However, the data we have presented suggest the current model is inadequate in many respects. Existing data that suggest transfers at 23 weeks of gestation do

Table 5 The median (range) length of stay for babies (in days) admitted alive to intensive care and dying before discharge from neonatal care

\begin{tabular}{|c|c|c|c|c|}
\hline \multirow[b]{2}{*}{ Birth year } & \multicolumn{4}{|c|}{ Gestation (weeks) } \\
\hline & 22 Median (range) & 23 Median (range) & 24 Median (range) & 25 Median (range) \\
\hline 1991-1995 & $1.0(1,17)$ & $2.0(1,144)$ & $2.0(1,197)$ & $3.0(1,132)$ \\
\hline 1996-2000 & $3.0(1,11)$ & $3.0(1,21)$ & $2.5(1,186)$ & $3.0(1,157)$ \\
\hline $2001-2005$ & $1.0(1,2)$ & $3.0(1,84)$ & $5.5(1,110)$ & $7.5(1,165)$ \\
\hline 2006-2010 & $79.0^{*}$ & $8.0(1,194)$ & $7.0(1,162)$ & $9(1,153)$ \\
\hline $\mathrm{p}$ Value & 0.33 & $<0.001$ & $<0.001$ & $<0.001$ \\
\hline
\end{tabular}

*This length of stay is calculated from one baby and should not be over interpreted. 
Table 6 The median (range) length of stay for babies (in days) who survived to discharge from neonatal care

\begin{tabular}{lllll}
\hline & \multicolumn{4}{c}{ Gestation (weeks) } \\
\cline { 2 - 5 } Birth year & 22 Median (range) & 23 Median (range) & 24 Median (range) & 25 Median (range) \\
\hline $1991-1995$ & - & $121.5(90,159)$ & $114.0(75,319)$ & $102.0(61,163)$ \\
$1996-2000$ & - & $124.0(82,162)$ & $125.5(87,176)$ & $104.0(23,201)$ \\
$2001-2005$ & - & $138.5(120,222)$ & $124.0(78,231)$ & $114.0(64,237)$ \\
$2006-2010$ & - & $134.5(104,231)$ & $110.0(79,214)$ & $109.0(49,233)$ \\
$p$ Value & - & 0.11 & 0.14 & 0.07 \\
\hline
\end{tabular}

no better than non-transfers are probably not a reliable guide to the likely impact of greater centralisation as the data, like ours, relate to a period where decisions to transfer were often made for a variety of reasons, such as a lack of space, and not simply to move the baby to a higher level of care/expertise. ${ }^{21}$

\section{LIMITATIONS}

While our work is based on a geographically defined population, data are limited to short-term outcomes. Although data are available from elsewhere on trends in longer term health status, these need careful interpretation, particularly in terms of the definitions used, the population included and the chosen denominator.

Missing, in terms of describing outcome in these children, both in our study and many others are the views of the parents. Describing success or failure in terms of alive or dead, disabled or not is clearly too simplistic and a greater understanding of how parents view the outcome of these children would clearly be helpful. Such views when produced in the lay press are typically polarised and hence may be both unrepresentative and misleading.

\section{CONCLUSION}

Our work generally agrees with the existing UK and other international guidelines and recommendations. However, if we are to improve our management of these babies, it would appear sensible to reconsider how and where their care is organised and delivered. Improving the package of care, as perceived by the family, will not necessarily improve survival or reduce morbidity.

Acknowledgements Sarah Seaton is a Research Methods Fellow supported by the National Institute for Health Research. Sophie King undertook this work while working as a Research Methods Intern supported by the National Institute for Health Research. The views expressed in this publication are those of the authors and not necessarily those of the NHS, the National Institute for Health Research or the Department of Health.

Contributors The initial concept was devised by DF. SS and SK undertook the statistical analysis and wrote the first draft of the paper. BM, ED and DF all made substantial contributions to conception and design. All authors contributed to interpretation of the data and the writing of the paper. SS is the guarantor.

\section{Funding NIHR.}

\section{Competing interests None.}

Ethics approval The Neonatal Survey is given permission to collect data by the Patient Information Advisory Group (Now the National Information Governance Board for Health and Social Care).

Provenance and peer review Not commissioned; externally peer reviewed.

Open Access This is an Open Access article distributed in accordance with the Creative Commons Attribution Non Commercial (CC BY-NC 3.0) license, which permits others to distribute, remix, adapt, build upon this work non-commercially, and license their derivative works on different terms, provided the original work is properly cited and the use is non-commercial. See: http://creativecommons.org/ licenses/by-nc/3.0/

\section{REFERENCES}

1 Nuffield Council on Bioethics. Critical care decisions in fetal and neonatal medicine: ethical issues, 2006.

2 Wilkinson AR, Ahluwalia J, Cole A, et al. Management of babies born extremely preterm at less than 26 weeks of gestation: a framework for clinical practice at the time of birth. Arch Dis Child Fetal Neonatal Ed 2009;94:F2-5.

3 Allen V, Levy A. 'Doctors told me it was against the rules to save my premature baby'. Avaliable online at: http://www.dailymail.co.uk/news/article-1211950/ Premature-baby-left-die-doctors-mother-gives-birth-just-days-22-week-care-limit. html. Daily Mail. UK, 2009 (accessed 16 Feb 2012).

4 Wishart A. Premature babies battle for survival at 'edge of life'. Online at: http://www. bbc.co.uk/news/health-12625253. BBC News, 2011 (accessed 24 October 2011).

5 Dutch Pediatric Association. Your extremely preterm baby, medical treatment and your role as a parent. Online at http://www.nvk.nl/Kwaliteit/Richtlijnenenindicatoren/ Richtlijnen/RichtlijnPerinataalbeleidbijextremevroeggeboo.aspx. 2010 (accessed 24 October 2011).

6 Hansard. Time Limit For Abortion. House of Commons Debates. 2008;476.

7 Riley K, Roth S, Sellwood M, et al. Survival and neurodevelopmental morbidity at 1 year of age following extremely preterm delivery over a 20-year period: a single centre cohort study. Acta Paediatr 2008;97:159-65.

8 Swamy R, Mohapatra S, Bythell M, et al. Survival in infants live born at less than 24 weeks' gestation: the hidden morbidity of non-survivors. Arch Dis Child Fetal Neonatal Ed 2010;95:F293-4.

9 Costeloe K, Hennessy E, Gibson AT, et al. The EPICure study: outcomes to discharge from hospital for infants born at the threshold of viability. Pediatrics 2000;106:659-71.

10 Moore T, Johnson S, Hennessy E, et al. The EPICure-2 Study: have neurodevelopmental outcomes improved after extremely preterm birth in England? A comparison of birth cohorts from 1995 and 2006 [Abstract]. PAS Annual Meeting, 2011, Denver, USA.

11 Eichenwald EC, Stark AR. Management and outcomes of very low birth weight. N Engl J Med 2008;358:1700-11.

12 Hack M, Costello DW. Trends in the rates of cerebral palsy associated with neonatal intensive care of preterm children. Clin Obstet Gynecol 2008;51:763-74.

13 Sauve RS, Robertson C, Etches $P$, et al. Before viability: a geographically based outcome study of infants weighing 500 grams or less at birth. Pediatrics 1998;101:438-45.

14 Robertson CM, Watt MJ, Yasui Y. Changes in the prevalence of cerebral palsy for children born very prematurely within a population-based program over 30 years. JAMA 2007;297:2733-40.

15 Bohin S, Draper ES, Field DJ. Impact of extremely immature infants on neonatal services. Arch Dis Child Fetal Neonatal Ed 1996;74:F110-3.

16 Rattihalli RR, Lamming CR, Dorling J, et al. Neonatal intensive care outcomes and resource utilisation of infants born $<26$ weeks in the former Trent region: 2001-2003 compared with 1991-1993. Arch Dis Child Fetal Neonatal Ed 2011;96: F329-34.

17 Khan RA, Burgoyne L, O'Connell MP, et al. Resuscitation at the limits of viabilityan Irish perspective. Acta Paediatr 2009;98:1456-60.

18 Sugiura T, Kouwaki M, Togawa Y, et al. Neurodevelopmental outcomes at 18 months' corrected age of infants born at 22 weeks of gestation. Neonatology 2011;100:228-32.

19 Lemons JA, Bauer CR, Oh W, et al. Very low birth weight outcomes of the National Institute of Child health and human development neonatal research network, January 1995 through December 1996. NICHD Neonatal Research Network. Pediatrics 2001;107:E1.

20 Wilson-Costello D, Friedman $\mathrm{H}$, Minich $\mathrm{N}$, et al. Improved neurodevelopmental outcomes for extremely low birth weight infants in 2000-2002. Pediatrics 2007;119:37-45.

21 Costeloe K, Hennessy E, Stacey F, et al. Survival of extremely preterm infants by hospital designation. Acta Paediatrica 2009;98(Suppl 460):13. 